\title{
Original
}

\section{Alterations in Sarcoplasmic Reticulum and Mitochondrial Functions in Stunned Myocardium: Relation between Regional Myocardial Function and Biochemical Analyses}

\author{
Hirohisa Arata, Eiichi Geshi, Haruhiko Ishioka and Takashi Katagiri
}

\begin{abstract}
We studied the contribution of intracellular microorgan dysfunction in the post ischemic stunned myocardium. In 47 mongrel dogs, LAD occlusion for $15 \mathrm{~min}(\mathrm{I}-15 \mathrm{~m})$ and subsequent reperfusion for $60 \mathrm{~min}$ (R-60m) were performed with simultaneous records of hemodynamics, coronary blood flow (CBF), regional myocardial blood flow (MBF) and segment shortening (SS). Sarcoplasmic reticulum (SR) and mitochondria (Mt) were analyzed using biochemical procedures. Hemodynamics indicated no remarkable changes throughout the experiment. CBF showed reactive hyperemia to $370 \%$ of control transiently after reprefusion, then returned to control level at R-15m. SS diminished to $-22 \%$ of control at I-15m, and it was still depressed at $58 \%$ at R-60m (stunning). Ca-ATPase activity of SR was reduced to $57 \%$ of control at $\mathrm{I}-15 \mathrm{~m}$, and remained depressed at $78 \%$ at R-60m. State III respiration of Mt decreased to $75 \%$ of control, and dinitrophenol-stimulated ATPase activity of Mt was $72 \%$ of control at $\mathrm{I}-15 \mathrm{~m}$. These activities did not recover completely at R-60m (77\% and $75 \%$, respectively). Both Ca-ATPase activity of SR and state III respiration of Mt were positively correlated to SS. SDS-gel electrophoresis of SR protein revealed no irreversible changes. These results suggested that contractile dysfunction after brief ischemia is related to the energy demand and supply, and the transient dysfunction of microorgans is one of the main causes of stunned myocardium.
\end{abstract}

Key words: stunned myocardium, reperfusion injury, sarcoplasmic reticulum, mitochondria, canine heart

\section{Introduction}

Reperfusion in the early stage of myocardial infarction is expected to improve the prognosis of patients of acute myocardial infarction (aMI). Percutaneous transluminal coronary angioplasty (PTCA) and percutaneous transluminal coronary recanalization (PTCR) have already been established in clinical practice. Reperfusion in the early stage of myocardial infarction has several complications, however, such as reperfusion arrhythmia, vascular damage, noreflow phenomenon and contractile dysfunction. Reperfusion injury after a brief period of myocardial ischemia termed "myocardial stunning"1), has prolonged, reversible regional contractile dysfunction without cell necrosis. Several hypotheses have been proposed as mechanisms of stunning. These include depletion of high energy phosphate ${ }^{2,3}$, dysfunction of sarcoplasmic reticulum ${ }^{4-6)}$, depressed calcium activation of contraction ${ }^{7)}$, calcium overThird Department of Internal Medicine, Showa University School of Medicine, 1-5-8 Hatanodai, Shinagawa-ku, Tokyo 142, Japan. 
$\operatorname{load}^{8)}$, and generation of free radicals ${ }^{9)}$. However all of these hypotheses remain inadequately explained. For example, a depressed exchange rate of cytosolic ADP for intramitochondrial ATP facilitated by adenine nucleotide translocase may be associated with a depressed rate of ATP synthesis by the mitochondria. The loss of mitochondrial respiration cannot be explained by the loss of adenine nucleotide translocase activity, because uncoupling between electron transport and ADP phosphorylation did not stimulate respiration above state III levels and oxidant stress can increase the permeability of mitochondria to calcium and lead to uncoupling ${ }^{10,11)}$. Other reports have stated that the sarcoplasmic reticulum shows a decrease in its $\mathrm{Ca}^{2+}$ accumulating activity with a reduction in the activity of the $\mathrm{Ca}^{2+}, \mathrm{Mg}^{2+}$-ATPase. A decrease in the amount of calcium stored in the sarcoplasmic reticulum as a result of a reduction in the calcium pump activity could diminish contractile protein activation through attenuated calcium release during systole ${ }^{12}$, while the activities of the sarcolemmal $\mathrm{Na}^{+}, \mathrm{K}^{+}$-ATPase and $\mathrm{Ca}^{2+}$-ATPase enzymes, and of the $\mathrm{Na}^{+} / \mathrm{Ca}^{2+}$ exchanger and $\mathrm{Na}^{+} / \mathrm{H}^{+}$antiporter remain fully functional. In the present study, we investigated the relation of the contractile functions in the stunned myocardium and the damage to microorgans, such as sarcoplasmic reticulum (SR) and mitochondria (Mt).

\section{Materials and Methods}

1) Instrument; Forty-seven mongrel dogs weighing 8 to $22 \mathrm{~kg}$ were anesthetized with intravenous injection of urethane $(450 \mathrm{mg} / \mathrm{kg}), \alpha$-chloralose $(45 \mathrm{mg} / \mathrm{kg})$ and diazepam $(10 \mathrm{mg})$. A left thoracotomy was performed under positive pressure respiration with room air using a Harvard type ventilator. The left anterior descending coronary artery (LAD) was isolated and a Doppler flow velocity probe (Triton Technology Inc., San Diego) was placed between the first and second diagonal branch to measure the coronary blood flow $(\mathrm{CBF})$. Pig tail and Swan-Gantz catheters were inserted into the femoral artery and saphenous vein, and heart rate (HR), left ventricular systolic pressure (LVP), LV dp/dt, pulmonary arterial pressure (PA) and cardiac output (CO) were recorded by the polygraph system (Nihon Kohden C.O., Tokyo). Regional myocardial blood flow (BMF) was determined by the $\mathrm{H}_{2}$ gas clearance method using a platinum electrode (Unique Medical Co. Ltd., Tokyo) inserted into subendocardial muscles of the ischemic (I) and the non-ischemic (NI) myocardium. Myocardial regional function was measured by a pair of piezoelectric crystals (Triton Technology Inc., San Diego) inserted at a depth of 7-9 $\mathrm{mm}$ into the subendocardium. Depths of crystal were verified at the end of each experiment. The distance between the two crystals was measured, and percent segment shortening (\% SS) was calculated using the equation,

$\% \mathrm{SS}=(\mathrm{EDSL}-\mathrm{ESSL}) / \mathrm{EDSL} \times 100$, where

ESSL is end systolic segment length, and EDSL is end diastolic segment length.

2) Experimental protocol; LAD was occluded by the snare for $15 \mathrm{~min}$ and subsequent reperfusion was performed for 60 min with continuous records of hemodynamics (HR, PAP, CO, LVP, LVEDP, and LVdp/dt), CBF and MBF.

3) Biochemical analyses; All of the procedures were carried out at $4{ }^{\circ} \mathrm{C}$ unless otherwise mentioned, and all the reagents were of reagent grade. The beating heart was removed at the end of $15 \mathrm{~min}$ ischemia, and after 15 to 60 min reperfusion, washed briefly with ice cold saline solution, and placed on crushed ice. The ischemia-reperfused and non-ischemic (control) myocardium were reserved and divided into subendocardium (Endo) and subepicardium (Epi). 
a) Preparation of the SR fraction; SR was extracted as the light microsomal fraction using the modified method of Harigaya-Schwartz ${ }^{13)}$. Briefly, three grams of heart muscle were minced with scissors and homogenized with a polytron homogenizer (Kinematica PT10/35) with 9 volumes of a solution containing $0.01 \mathrm{M} \mathrm{NaHCO}, 0.05 \mathrm{M} \mathrm{NaN}_{3}$, and $0.001 \mathrm{M}$ ethylene glycol tetraacetic acid (EGTA). The homogenate was centrifuged at $9,000 \times \mathrm{g}$ (Hitachi himac CR21) for $10 \mathrm{~min}$ and the supernatant was centrifuged again at $12,000 \times \mathrm{g}$ for $10 \mathrm{~min}$ to remove the lysosome rich fraction. The resulting supernatant was ultracentrifuged at $120,000 \times \mathrm{g}$ (Hitachi 55P-72) for $45 \mathrm{~min}$ twice. The precipitate obtained was regarded as SR. The SR fraction was suspended in $0.05 \mathrm{M} \mathrm{KCl}$ and $0.02 \mathrm{M} \mathrm{N}$-trismethyl 2-aminoethane sulfonic acid (TES)-tris ( $\mathrm{pH}$ 7.0), and the protein concentration was determined by the biuret procedure.

b) $\mathrm{Ca}^{2+}$-stimulated ATPase activity and SDS gel electrophoresis of $\mathrm{SR} ; \mathrm{Ca}^{2+}$-stimulated ATPase activity of SR was determined according to the modified method of Harigaya and Schwartz ${ }^{13)}$, which was expressed as a difference of the activities in the presence of $2 \times$ $10^{-5} \mathrm{M} \mathrm{CaCl}_{2}$ or $0.001 \mathrm{M}$ EGTA in the solution containing $0.1 \mathrm{M} \mathrm{KCl}, 0.01 \mathrm{M} \mathrm{MgCl}_{2}$, $0.005 \mathrm{M} \mathrm{NaN}_{3}, 30 \mathrm{mM} \mathrm{ATP}$ and $0.02 \mathrm{M}$ TES-tris $\left(\mathrm{pH} 7.0\right.$ ) at $37^{\circ} \mathrm{C}$ for $15 \mathrm{~min}$. Inorganic phosphate liberated from ATP was measured by the modified method of Fiske-SubbaRow ${ }^{14)}$.

SDS Gel electrophoresis of SR composing proteins; electrophoresis of SR proteins was carried out in the presence of SDS with $10 \%$ polyacrylamide by the modified method of Laemmli using silver stain ${ }^{15)}$.

c) Preparation of mitochondria; Mitochondria were prepared by the modified method of Sordahl and Stewart ${ }^{16)}$ utilizing alkaline protease (Nagarse, Nagase Biochemicals Ltd., Tokyo) as follows. Briefly, three grams of heart muscles were minced with scissors and homogenized with 9 volumes of a solution containing $0.25 \mathrm{M}$ sucrose, $0.01 \mathrm{M}$ EGTA, and $0.03 \mathrm{M}$ tris$\mathrm{HCl}(\mathrm{pH} 7.2$ ) with a polytron homogenizer and centrifuged at $27,000 \times \mathrm{g}$ (Hitachi himac CR21) for $10 \mathrm{~min}$. One $\mathrm{mg}$ of Nagarse per gram of starting heart tissue was added to the pellet and incubated at $4{ }^{\circ} \mathrm{C}$ for $8 \mathrm{~min}$, and $40 \mathrm{ml}$ of a solution containing $0.18 \mathrm{M} \mathrm{KCl}, 0.01$ M EGTA, $0.5 \%$ (wt/vol) bovine serum albumin (BSA), and $0.03 \mathrm{M}$ tris- $\mathrm{HCl}(\mathrm{pH} 7.2$ ) were added, then homogenized twice with a motor driven teflon pestle and centrifuged at $500 \times \mathrm{g}$ for $5 \mathrm{~min}$. After filtration using cheese cloth, and centrifugation twice at $12,000 \times \mathrm{g}$ at 10 min a solution containing $0.18 \mathrm{M} \mathrm{KCl}$, and $0.03 \mathrm{M} \mathrm{Tris-HCl}(\mathrm{pH} \mathrm{7.2),0.5 \%} \mathrm{(wt/vol)} \mathrm{was}$ added for a final concentration of approximately $15 \mathrm{mg} / \mathrm{ml}$.

d) Oxidative phosphorylation of mitochondria; Mitochondrial oxidative phosphorylation was measured with an oxygen electrode (Oxygen Consumption Recorder PO-100A, Yanagimoto Mfg. Co. Ltd., Kyoto), according to the method of Hagihara ${ }^{17)}$. The reaction medium contained $0.01 \mathrm{M} \mathrm{KCl}, 1 \mathrm{mM}$ ethylenediaminetetraacetic acid (EDTA), $2 \mathrm{mM} \mathrm{MgCl} 2,0.25 \mathrm{M}$ sucrose and $0.02 \mathrm{M}$ potassium phosphate buffer $(\mathrm{pH} 7.2)$ at $25^{\circ} \mathrm{C}$. Succinate or glutamate plus malate were used as substrates and ADP was added to estimate oxidative phosphorylation. Oxygen consumption rates in states III and IV were determined from a polarographic record by the method of Chance and Williams ${ }^{18}$.

e) ATPase activity of mitochondria; Dinitrophenol (DNP)-stimulated ATPase activity of mitochondria was examined by the modified method of Pullman et al. ${ }^{19)}$ in a reaciton medium containing $0.21 \mathrm{M}$ sucrose, $0.02 \mathrm{M} \mathrm{KCl}, 0.02 \mathrm{M}$ tris-malate $(\mathrm{pH} 7.2)$ and $5 \mathrm{mg}$ of mitochondria. The reaction was started by the addition of $0.001 \mathrm{M}$ DNP and $0.03 \mathrm{M}$ ATP at $25^{\circ} \mathrm{C}$, and the amount of phosphate liberated in the reaction was assayed by the method of Fiske and SubbaRow ${ }^{14)}$. 
4) Statistical Analyses; Results were expressed as mean \pm standard deviation of experimental indicators. ANOVA for repeated measurements was used to determine the significance of changes during time-dependent multiple observations. Student's $t$-test was used to compare changes between the two groups, where $p$ values less than 0.05 were considered as significantly different.

\section{Results}

Hemodynamics; During $15 \mathrm{~min}$ occlusion and subsequent reperfusion for $60 \mathrm{~min}$, no significant hemodynamics (HR, PAP, CO, LVP, LVEDP, and LVdp/dt) changes occurred (Fig. 1).

Coronary blood flow (CBF) and regional myocardial blood flow (MBF); CBF and MBF of ischemia-reperfused area were summarized in Fig. 2. No significant changes of CBF and MBF were observed in the non-ischemic region throughout the experiment. CBF was 25.0土 $12.6 \mathrm{ml} / \mathrm{min}$ in the preocclusion (control). During coronary occlusion, CBF indicated zero, and at just after reperfusion CBF showed transient reactive hyperemia of about $370 \%$ $(92.9 \pm 51.9 \mathrm{ml} / \mathrm{min})(\mathrm{P}<0.01)$ of the control value, and then returned to control level after $15 \mathrm{~min}$ reperfusion. $\mathrm{MBF}$ was $114.0 \pm 19.1 \mathrm{ml} / 100 \mathrm{~g} / \mathrm{min}$ in the control. During ischemia, MBF decreased remarkably to $19.0 \pm 9.9 \%(\mathrm{P}<0.01)$ of control. MBF showed transient reactive hyperemia to $134.2 \pm 17.5 \%(\mathrm{P}<0.01)$ at $5 \mathrm{~min}$ reperfusion. After that, it was reduced to below the control value, and indicated $75.4 \pm 18.5 \%$ of control at $60 \mathrm{~min}$ reperfusion.

$\%$ Segment shortening (\%SS); Regional myocardial contractile functions indicated by \% segment shortening (\%SS) are summarized in Fig. 3. No significant changes occurred in the
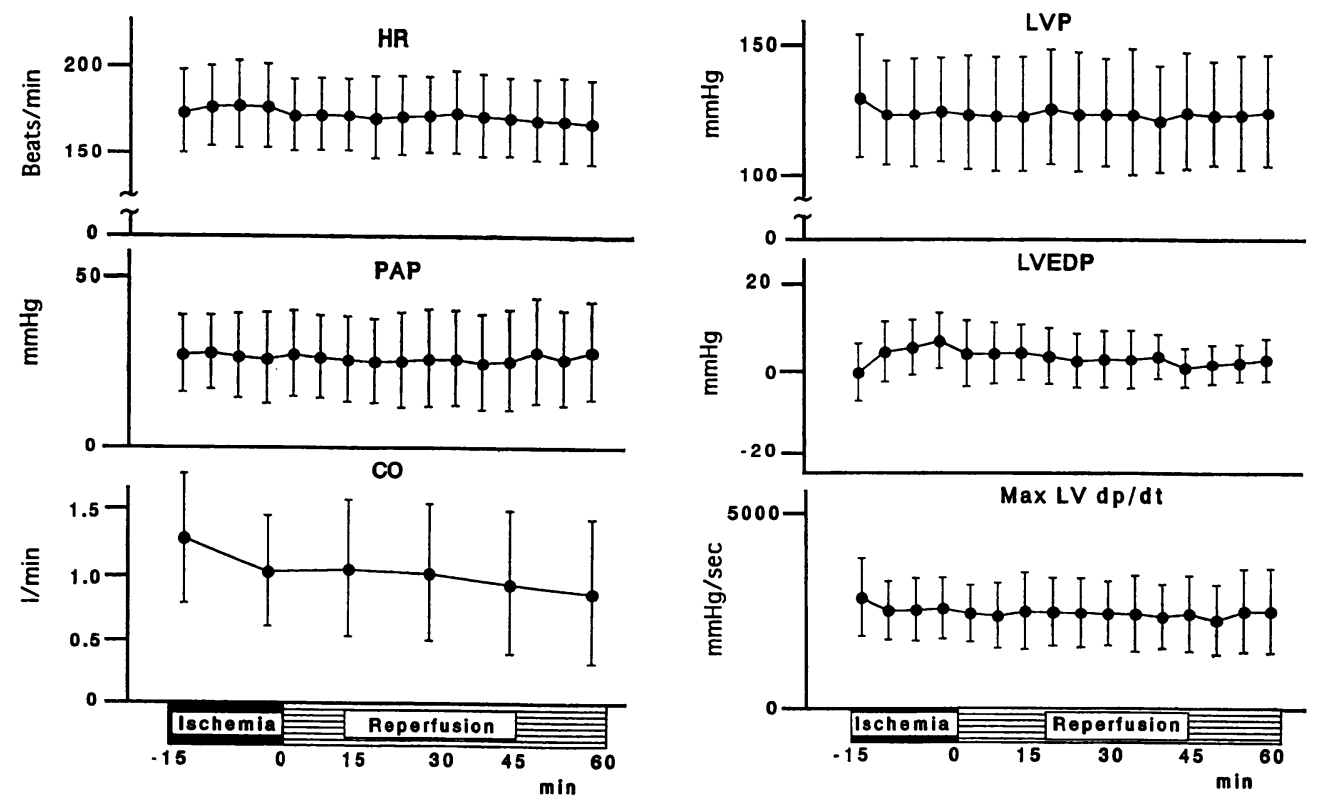

Fig. 1. Hemodynamic changes during ischemia and reperfusion.

HR; heart rate, PAP; pulmonary artery pressure, CO; cardiac output, LVP; left ventricular pressure, LVEDP; left ventricular end-diastolic pressure, Max LVdp/dt; max left ventricular $\mathrm{dp} / \mathrm{dt}$. 


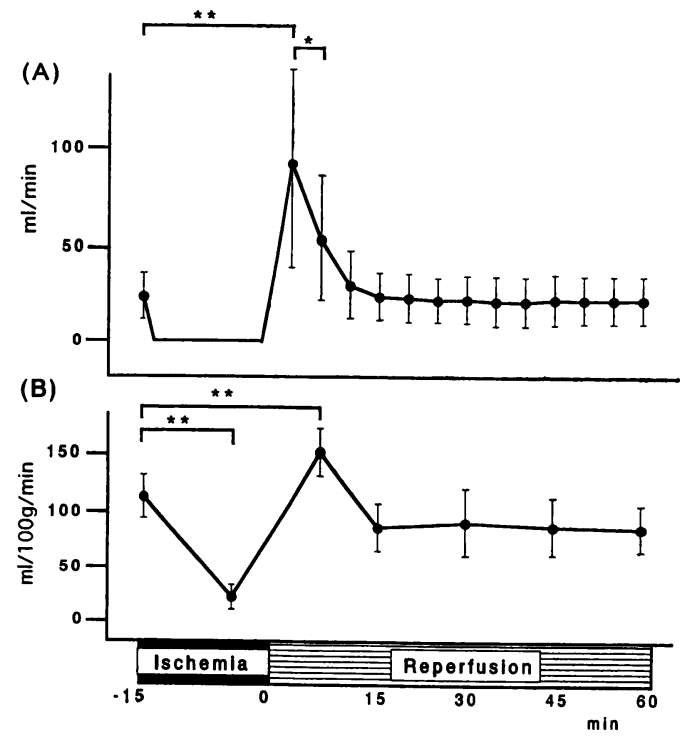

Fig. 2.

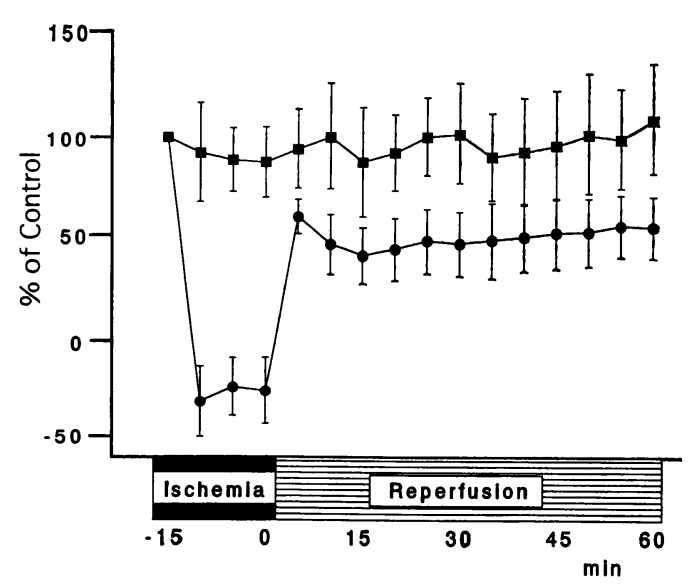

Fig. 3.

Fig. 2. Coronary blood flow and myocardial blood flow.

(A); coronary blood flow of left anterior descending artery during ischemia and reperfusion.

(B); myocardial blood flow of ischemia-reperfusion regional myocardium.

$* \mathrm{p}<0.05, * * \mathrm{p}<0.01$ vs non-ischemia.

Fig. 3. \% Segment shortening during ischemia and reperfusion.

-—; Ischemic myocardium. - $\mathbf{\square}$; Non-ischemic myocardium.

Plots indicate \% of control.

NI region throughout the experiment. In the ischemic myocardium at the end of $15 \mathrm{~min}$ ischemia, \% SS showed $-22.5 \pm 30.5 \%(\mathrm{P}<0.01)$ of prevoius control, indicating dyskinesis and bulging of the myocardium. At 5 min reflow, \%SS showed transient improvement to $59.2 \pm 15.5 \%$, however, $\%$ SS decreased again to $40.2 \pm 26.3 \%$ at $15 \mathrm{~min}$ reflow, and $54.2 \pm$ $30.2 \%(\mathrm{P}<0.01)$ at $60 \mathrm{~min}$ reflow, which implied stunning.

$\mathrm{Ca}^{2+}$-ATPase activity of SR; $\mathrm{Ca}^{2+}$-ATPase activities of the SR fraction are shown in Fig. 4. Yields of SR protein did not differ between the ischemia-reperfused and non-ischemic myocardium. In the non-ischemic myocardium, $\mathrm{Ca}^{2+}$-ATPase activity was $10.9 \pm 1.4 \mu$ moles $\mathrm{Pi} / \mathrm{mg}$ protein/hr in Endo, and 13.3 \pm 2.1 in Epi. $\mathrm{Ca}^{2+}$-ATPase activity at $15 \mathrm{~min}$ ischemia was significantly reduced to $5.7 \pm 1.3(\mathrm{P}<0.01)$ in Endo and $6.0 \pm 1.4(\mathrm{P}<0.01)$ in Epi. After the reflow, this activity in Endo still depressed to $8.0 \pm 0.7(\mathrm{P}<0.05)$ at $60 \mathrm{~min}$ reperfusion. The activity in Epi was also still depressed at $9.2 \pm 1.7(\mathrm{P}<0.05)$ at $60 \mathrm{~min}$ reperfusion. The relation between $\mathrm{Ca}^{2+}$-ATPase activity of SR and \%SS showed a significant and positive correlation (Fig. 5), and this suggested that the Ca uptake of SR was related to the regional myocardial function after the short period of ischemia.

SDS gel electrophoresis of SR; Electrophoresis of SR is shown in Fig. 6. A major ATPase protein was identified with the standard of about 100,000 daltons. There were neither compositional changes in the major ATPase protein nor the appearance of the new band in all cases. 


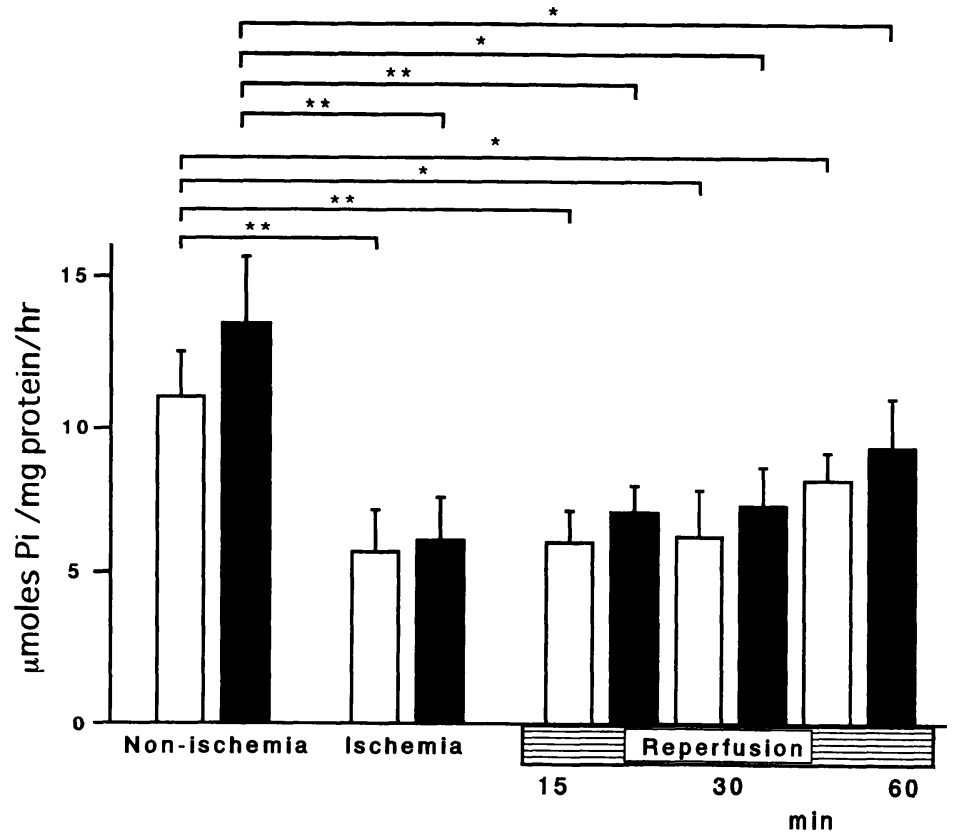

Fig. 4. $\mathrm{Ca}^{++}$-ATPase activity of SR.

$\square$; subendocardium. $\square$; subepicardium. ${ }^{*} \mathrm{p}<0.05,{ }^{* *} \mathrm{p}<0.01$ vs non-ischemia.

(A) (Endocardium)

$y=0.0587 x+5.368, r=0.777$

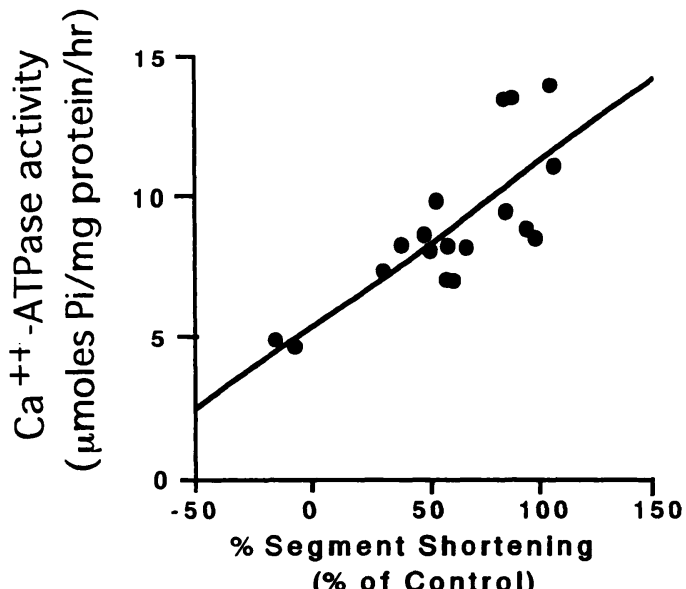

(B) (Epicardium)

$y=0.0589 x+6.804, r=0.681$

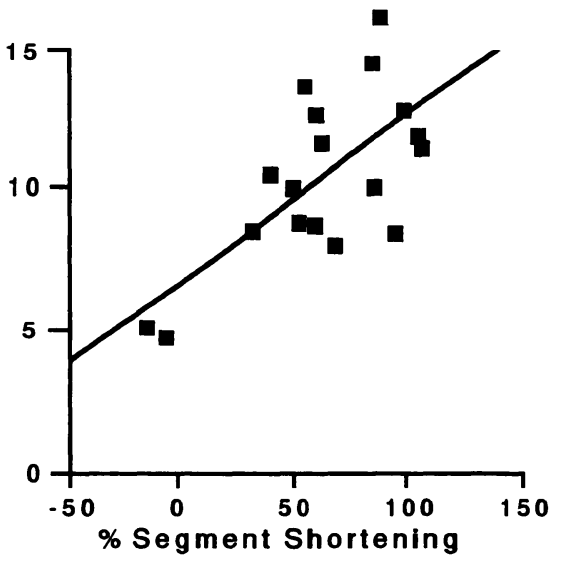

(\% of Control)

Fig. 5. Correlation between $\mathrm{Ca}^{++}$-ATPase activity of SR and \% Segment shortening (SS).

(A); $\mathrm{Ca}^{2+}$-ATPase activity of subendocardium vs \%SS.

(B); $\mathrm{Ca}^{2+}$-ATPase activity of subepicardium vs $\% \mathrm{SS}$. 


\section{ATPase}
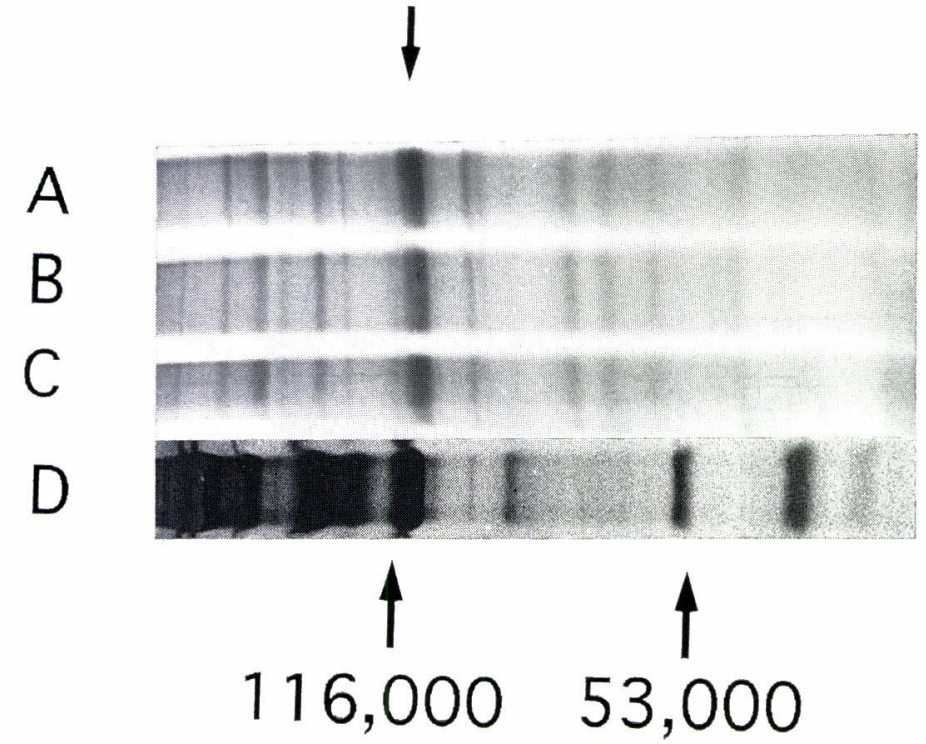

Fig. 6. SDS gel ( $10 \%$ acrylamide) electrophoresis of SR protein. Molecular weight standards were as follows; $116 \mathrm{kDa}: \beta$-galactosidase. $53 \mathrm{kDa}$ : glutamic dehydrogenase. Major band $(=100 \mathrm{kDa})$ indicates ATPase protein.

A; Non-ischemia, B; $15 \mathrm{~min}$ ischemia, C; $15 \mathrm{~min}$ ischemia and $60 \mathrm{~min}$ reperfusion, D; Molecular Marker.

Mitochondrial respiratory activity; The oxygen consumption rates in state III of mitochondria, using succinate or glutamate plus malate as substrates, are presented in Fig. 7. In the non-ischemic myocardium, state III respiratory activities were $197.5 \pm 27.4 \mathrm{~m} \mu$ atoms $0 / \mathrm{mg}$ protein $/ \mathrm{min}$ in Endo and 199.5 \pm 33.6 in Epi, using succinate as the substrate. State III respiratory activities with glutamate plus malate as the substrate indicated $198.4 \pm 42.7$ in Endo and 207.6 \pm 39.3 in Epi, respectively. At $15 \mathrm{~min}$ ischemia, state III respiratory activity of mitochondria using succinate was reduced significantly to $75.4 \pm 17.7 \%(\mathbf{P}<0.05)$ in Endo, and $71.3 \pm 13.9 \%(\mathbf{P}<0.05)$ in Epi compared with non-ischemic myocardium. These activities showed $79.1 \pm 8.6 \%(\mathrm{P}<0.05)$ and $73.5 \pm 9.1 \%(\mathrm{P}<0.05)$ of control at $60 \mathrm{~min}$ reflow, respectively. The respiratory consumption index (RCI) revealed changes similar to the state III respiratory activity and the oxygen consumption rate in state IV indicated no significant change during ischemia-reperfusion (data not shown). Using glutamate plus malate as the substrate, state III respiratory activities indicated patterns similar to those with succinate as the substrate, $(72.6 \pm 16.7 \%(\mathrm{P}<0.05)$ in Endo and $73.3 \pm 13.4 \%$ in Epi at $15 \mathrm{~min}$ ischemia), showing $87.1 \pm 28.0 \%$ in Endo and $76.4 \pm 26.4 \%$ in Epi at $60 \mathrm{~min}$ reflow, respectively. The relation between mitochondrial state III respiratory activity in succinate and \% segment shortening showed a significant positive correlation (Fig. 8). This suggested that the mitochondrial respiratory function was also related to regional myocardial function of the stunned myocardium.

Dinitrophenol (DNP)-stimulated ATPase activity; DNP-stimulated ATPase activities are shown in Fig. 9. In the non-ischemic myocardium, this activity indicated $11.2 \pm 1.27$ in 


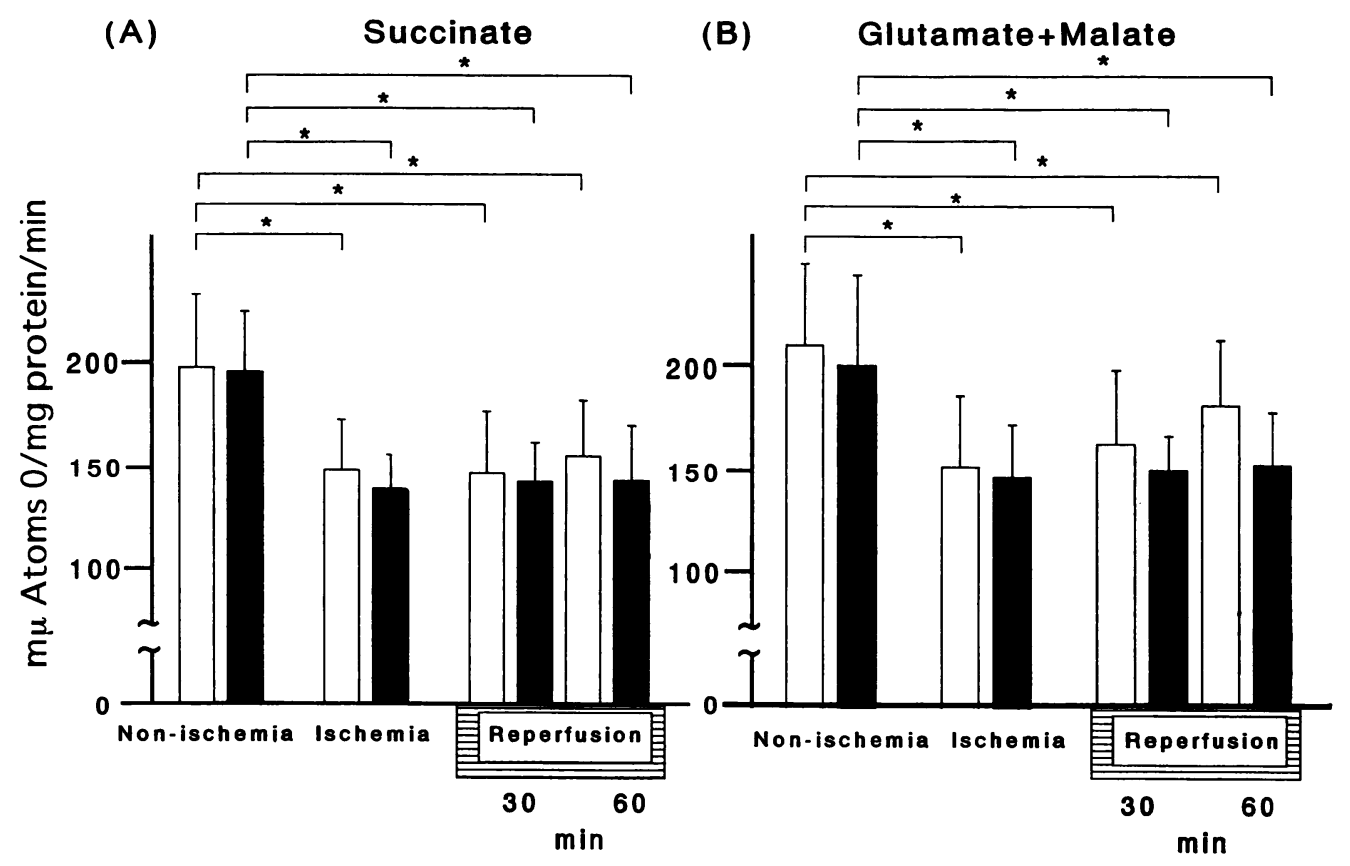

Fig. 7. State III respiration of mitochondria.

(A); succinate was used as the substrate.

(B); glutamate plus malate was used as the substrate.

$\square$; subendocardium. $\square$; subepicardium. ${ }^{*} \mathrm{p}<0.05$, vs non-ischemia.

Epi. In the $15 \mathrm{~min}$ ischemia, this activity was reduced significantly to $76.1 \pm 11.2 \%(\mathbf{P}<0.01)$ of control in Endo. The low activity continued at $60 \mathrm{~min}$ reflow, of which the value was $79.0 \pm 8.0 \%(\mathrm{P}<0.05)$ of control. DNP-stimulated ATPase activity in Epi decreased to $73.6 \pm 13.5 \%(\mathrm{P}<0.01)$ of control $15 \mathrm{~min}$. This activity did not recover at $60 \mathrm{~min}$ reflow $(74.4 \pm 6.4 \%(\mathrm{P}<0.05))$.

\section{Discussion}

Following a brief period of ischemia, prolonged ventricular dysfunction without necrosis, is a phenomenon known as "stunned myocardium"1). In stunned myocardium, the situation is defined as reduced myocardial function, normal coronary blood flow, full recovery outcome after a period of hours to several days, and reversible ischemic injury. The mechanisms responsible for myocardial stunning have been pursued, but the single cause has not been established. A number of mechanisms have been suggested, such as reduced ability to resynthesize high-energy phosphates ${ }^{20)}$, impaired sympathetic neural responsiveness ${ }^{21)}$, heterogeneous impairment of regional perfusion, loss of creatine kinase activity and impaired utilization of energy by the myofibrils ${ }^{22)}$, leukocyte activation ${ }^{23)}$, decreased sensitivity of the myofilaments to calcium $^{24)}$, transient intracellular calcium overload ${ }^{8)}$, and free radicals ${ }^{9}$. However all hypotheses remain unclarified.

The experiments in this study showed that during $15 \mathrm{~min}$ ischemia, \%SS reduced from $-20 \%$ to $-30 \%$ of the previous control, however, after transient improvement, prolonged postischemic ventricular dysfunction from $50 \%$ to $60 \%$ continued at 60 min reflow (stun- 

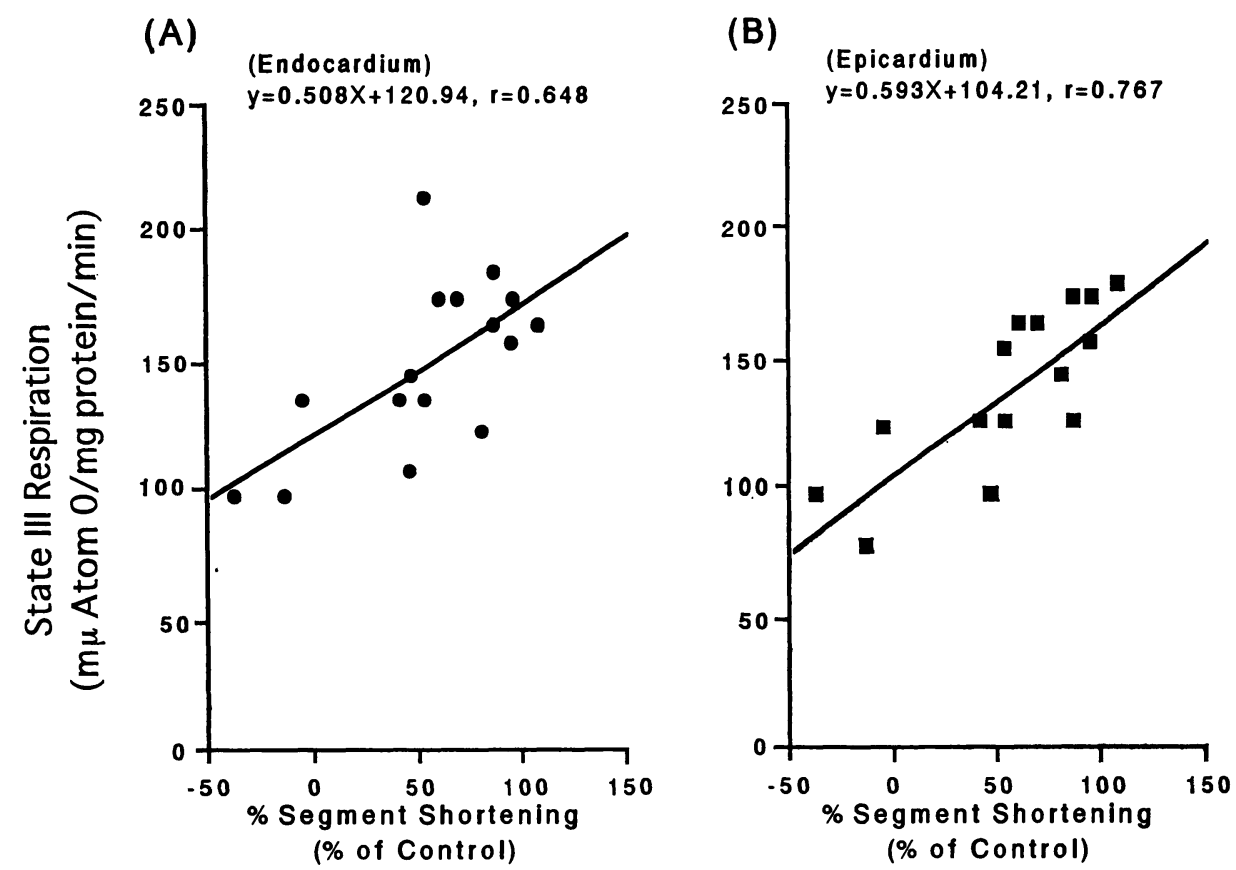

Fig. 8. Correlation between state III respiration of mitochondria (succinate as the substrate) and \% Segment shortening (SS).

(A); State III respiration of subendocardium vs \%SS.

(B); State III respiration of subepicardium vs \%SS.

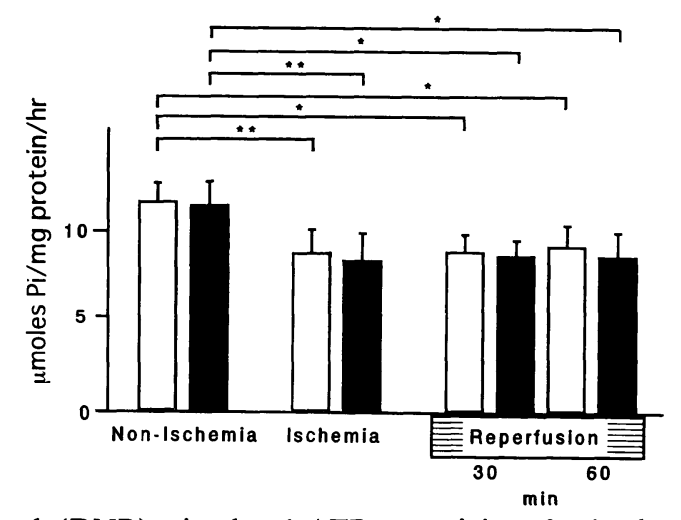

Fig. 9. Dinitrophenol (DNP)-stimulated ATPase activity of mitochondria.

$\square$; subendocardium. $\square$; subepicardium. ${ }^{* *} \mathrm{p}<0.01, * \mathrm{P}<0.05$ vs non-ischemia.

ning). This reversible myocardium had no irreversible ultrastructural observation recognizable such as mild intracellular edema and slight mitochondrial swelling that have been reported likely to be the reversible changes; there was no appearance of mitochondrial dense deposits and contraction band necrosis which have been regarded to be irreversible changes (not shown). On the other hand, in our previous studies, we reported that the reduction of $\mathrm{Ca}^{2+}$-ATPase activity of sarcoplasmic reticulum (SR), as an energy demand system, with 
degradation of major ATPase protein and phospholipids of SR and a decrease of mitochondrial respiratory activities, as an energy supply system, are the indexes of ischemic irreversible changes in experimental acute myocardial ischemia, as early as at $20 \mathrm{~min}$ of coronary occlusion in Endo ${ }^{25)}$. These findings supported that the duration of $15 \mathrm{~min}$ ischemia is a reasonable period for the experimental model of myocardial stunning.

The data of the present paper suggest that the decrease of $\mathrm{Ca}^{2+}$-ATPase activity of SR, which is the major energy consuming enzyme next to myosin ATPase, decreased of Cauptake $^{6}$ ) and the inhibitor of Ca-release and Ca-coupling to myocyte with the reduction of $\mathrm{Ca}$ storage of $\mathrm{SR}^{5)}$. Then a decreased sensitivity of the myofilaments to cytosolic free $\mathrm{Ca}$ support the excitation contraction uncoupling ${ }^{7}$ due to dysfunction of SR. Also these results suggested that the decrease in the amount of calcium stored in the SR as a result of a reduction in the calcium pump activity and inhibition of the uptake of calcium by SR could diminish contractile protein activation and inhibition of uptake of calcium through attenuated calcium release during systole. We speculated that the mechanisms of inactivation of $\mathrm{Ca}^{2+}-$ ATPase without protein degradation were the decreased $\mathrm{Ca}^{2+}$ sensitivity of the myofibrils or an uncoupling between the $\mathrm{Ca}^{2+}$-ATPase and the cross-bridge cycles.

On the other hand, the mitochondria can play an important part in energy production and in the regulation of intracellular calcium. During ischemia the absence of oxidative phosphorylation trusts in net degradation of ATP to ADP and AMP. Cytosolic AMP degraded to nucleosides and purine bases results in the net loss of adenine nucleotide in the cytosol. Adenosine may replenish the mitochondrial ATP pool, which is essential for ATP synthesis, although only comprising $15-20 \%$ of the total cellular pool ${ }^{11)}$. Mitochondria maintain the viability of reoxygenated cells by buffering changes in cytosolic $\mathrm{Ca}^{2+}$. The oxygen dependent influx of cytosolic $\mathrm{Ca}^{2+}$ is probably mediated through the $\mathrm{Na}^{+} / \mathrm{Ca}^{2+}$ exchange protein. Metabolic recovery occurs with partial restoration of ATP levels ${ }^{26)}$, and reoxygenation in associated with a decrease in the efficiency of electron transfer at the level of $\mathrm{NADH}-\mathrm{CoQ}$ reductase in the mitochondrial inner membrane and an increase in the intramitochondrial $\mathrm{Ca}^{2+}$ content ${ }^{27)}$. The present study showed that at after $15 \mathrm{~min}$ ischemia, mitochondrial respiraiton was decreased significantly, and this reduced respiration continued after $60 \mathrm{~min}$ reperfusion. These data support that the stunning was related to the reduced function of mitochondria, which are the major energy production. During ischemia, intracellular levels of ATP are decreased, and the decreased level of cellular ATP persisted for a long time in stunned myocardium. Between the change of the ATP level and contractile recovery, similar time course are permitted ${ }^{28)}$. The delayed resynthesis of ATP is in turn the probable consequence of the loss of adenosine ${ }^{\text {i) }}$ and related compounds during the ischemic period. These results indicated that the attribution of mitochondrial resipratory dysfunction and uncoupling between eletcron transport and mitochondrial ATPase played a role in ATP depletion ${ }^{29)}$.

In subsequent experiments, these reduced activities of SR and $\mathrm{Mt}$ and regional myocardial function recovered to the control values at 7 days reperfusion ${ }^{30)}$. So we suggested that these biochemical analyses of subcellular microorgans were suitable to clarify the mechanism of myocardial stunning.

We conclude that the contractile function after brief reversible ischemia is correlated to SR and Mt functions that indicate indexes of energy demand and supply, and SR and Mt dysfunctions are one of the main causes in stunned myocardium. 


\section{Acknowledgement}

This work was supported in part by grants from the science research funds of the Department of Education (1992, C 745) and the Vehicle Racing Commemorative Foundation, Japan. The authors greatly thank Drs. M. Tomita, S. Itoh, S. Mukae, N. Konno, and T. Yanagishita for their collaborations and helpful discussions.

\section{References}

1) Braunwald E and Kloner RA: The stunned myocardium: prolonged, postischemic ventricular dysfunction. Circulation, 66: 1146-1149 (1982)

2) Reimer KA, Hill ML and Jennings RB: Prolonged depletion of ATP and of the adenine nucleotide pool due to delayed resynthesis of adenine nucleotides following reversible myocardial ischemic injury in dogs. J Mol Cell Cardiol, 242: H818-H826 (1981)

3) Jennings RB, Schaper J, Hill ML, Steenbergen C and Reimer KA: Effect of reperfusion late in the phase of reversible ischemic injury: changes in cell volume, electrolytes metabolites, and ultrastructure. Circ Res, 56: 262-278 (1985)

4) Rowe GT, Manson NH, Caplan M and Hess ML: Hydrogen peroxide and hydroxyl radical mediation of activated leukocyte depression of cardiac sarcoplasmic reticulum. Participation of the cyclooxygenase pathway. Cir Res, 53: 584-591 (1983)

5) Krause SM, Jacobus WE and Becker LC: Alterations in cardiac sarcoplasmic reticulum calcium transport in the postischemic "stunned" myocardium. Circ Res, 65: 526-530 (1989)

6) Kaplan P, Hendrikx M, Mattheussen M, Mubagwa K and Flaming W: Effects of ischemia and reperfusion on sarcoplasmic reticulum calcium uptake. Circ Res, 71: 1123-1130 (1992)

7) Kusuoka H, Koretsune Y, Chacko VP, Weisfeldt ML and Marban E: Excitation-contraction coupling in postischemic myocardium; Does failure of activator $\mathrm{Ca}^{2+}$ transients underlie stunning. Circ Res, 66: 1268-1276 (1990)

8) Steenbergen C, Murphy E, Watts JA and London RE: Correlation between cytosolic free calcium, contracture, ATP, and irreversible ischemic injury in perfused rat heart. Circ Res, 66: 135-146 (1990)

9) Bolli R, Patel BS, Jeroudi MO, Lai EK and MaCay PB: Demonstration of free radical generation in "stunned" myocardium of intact dogs with the use of spin trap $\alpha$-phenyl $\mathrm{N}$-tert-butyl nitrone. $J$ Clin Invest, 82: 476-485 (1988)

10) Zucchi R, Yu G, Ronca-Testoni S, Mariani M and Ronca G: Energy metabolism in myocardial stunning. J Mol Cell Cardiol, 24: 1237-1252 (1992)

11) Asimakis GK, Zwischenberger JB, Inners-McBride K, Sordahl LA and Conti VR: Postischemic recovery of mitochondrial adenine nucleotides in the heart. Circulation, 85: 2212-2220 (1992)

12) Limbruno U, Zucchi R, Ronca-Testoni S, Galbani P, Ronca G and Mariani M: Sarcoplasmic reticulum function in the "stunned" myocardium. J Mol Cell Cardiol, 21: 1063-1072 (1989)

13) Harigaya $S$ and Schwartz A: Rate of calcium binding and uptake in normal animal and failing human cardiac muscle. Membrane vesicles (relaxing system) and mitochondria. Cir Res, 25: 781794 (1969)

14) Fiske $\mathrm{CH}$ and SubbaRow Y: The colorimetric determination of phosphorus. J Biol Chem, 66: 375$400(1925)$

15) Laemmli UK: Cleavage of structural proteins during the assembly of the head of bacteriophage, T4. Nature, 227: 680-685 (1970)

16) Sordahl LA and Stewart ML: Mechanism(s) of altered mitochondrial calcium transport in acutely ischemic canine hearts. Circ Res, 47: 814-820 (1980)

17) Hagihara B: Techniques for the application of polarography to mitochondrial respiration. Biochim Biophys Acta, 46: 134-142 (1961)

18) Chance B and Williams GR: Respiratory enzymes in oxidative phosphorylation. I. Kinetic of oxygen utilization. J Biol Chem, 217: 383-393 (1955)

19) Pullman ME, Penefsky HS, Datta A and Racker E: Partial resolution of the enzymes catalying oxidative phosphorylation. I. Purification and properties of soluble dinitrophenol-stimulated adeno- 
sine triphosphatase. J Biol Chem, 235: 3322-3329 (1960)

20) Zughaib ME, Abd-Elfattah AS, Jeroudi MO, Sun JS, Sekili S, Tang X and Bolli R: Augmentation of endogenous adenosine attenuates myocardial stunning' independently of coronary flow of hemodynamic effects. Circulation, 88: 2359-2369 (1993)

21) Ciuffo AA, Ouyang P, Becker LC, Levin L and Weisfeldt ML: Reduction of sympathetic inotropic response after ischemia in dogs: Contributor to stunned myocardium. J Clin Invest, 75: 1504-1509 (1985)

22) Greenfield RA and Swain JL: Disruption of myofibrillar energy use; dual mechanisms that may contribute to postischemic dysfunction in stunned myocardium. Circ Res, 60: 283-289 (1987)

23) Engler $R$ and Covell JW: Granulocytes cause reperfusion ventricular dysfunction after 15 minute ischemia in the dog. Circ Res, 61: 20-28 (1987)

24) Hofmann PA, Millar WP and Moss RL: Altered calcium sensitivity of isometric tension in myocytesized preparations of porcine postischemic stunned myocardium. Circ Res, 72: $50-56$ (1993)

25) Katagiri T, Geshi E, Yanagishita T, Konno N and Tanno H: Symposium on pathophysiology in the early stage of acute myocardial infarction and treatment. Jpn Circ J, 52: 655-663

26) Hardy L, Clark JB, Darley-Usmar VM, Smith DR and Stone D: Reoxygenation dependent decrease in mitochondrial NADH: CoQ reductase (Complex I) activity in the hydroxic/reoxygenated rat heart. Biochem J, 274: 133-137 (1991)

27) Stone D, Darley-Usmar VM, Smith DR and O'Leary VJ: Hypoxia-reoxygenation induced increase in cellular $\mathrm{Ca}^{2+}$ in myocytes and perfused hearts: the role of mitochondria. $\mathrm{J} \mathrm{Mol} \mathrm{Cell} \mathrm{Cardiol,} \mathrm{21:}$ 963-973 (1989)

28) Deboer FWV, Ingwall JS, Kloner RA and Braunwald E: Prolonged derangements of canine myocardial purine metabolism after a brief coronary artery occlusion not associated with anatomic evidence of necrosis. Proc Natl Acad Sci, 77: 5471-5475 (1980)

29) Jennings RB, Reimer KA and Steenbergen C: Effect of inhibition of the mitochondrial ATPase on net myocardial ATP in total ischemia. J Mol Cell Cardiol, 23: 1383-1395 (1991)

30) Katagiri $T$, Arata $H$, Ishioka $H$, Itoh $S$ and Geshi $E$ : Adaptive behavior of the ischemic myocardium. Pathophysiology of the heart muscle after short-term ischemia and reperfusion. Ther Res, 15: 4046-4052 (1994) 